\title{
SELEÇÃO PARA TOLERÂNCIA AO ALUMÍNIO EM MILHO COM BASE EM PARÂMETROS GENÉTICOS E ANÁLISE MULTIVARIADA (1)
}

\author{
LÉO DUC HAA CARSON SCHWARTZHAUPT DA CONCEIÇÃO $\left(^{2}\right)$; \\ LARISSA MACEDO WINKLER DOERR ( ${ }^{(3)}$; JOSÉ FERNANDES BARBOSA NETO $\left(\left(^{*}\right)\right.$
}

\begin{abstract}
RESUMO
O melhoramento de plantas, nos últimos 40 anos, tem empenhado esforços na busca de genótipos de milho com tolerância ao alumínio. A compreensão da variabilidade existente através da distância genética entre genótipos serve como base para definição de cruzamentos que possibilitem a obtenção de ganho genético. O objetivo deste trabalho foi estudar o caráter tolerância ao alumínio em milho com base em parâmetros genéticos e estatística multivariada em gerações precoces. Para tanto foi realizada a estimativa de parâmetros genéticos e análise multivariada em 74 famílias $\mathrm{F}_{3: 2}$ originadas de dois cruzamentos contrastantes para o caráter tolerância ao alumínio. A estimativa dos parâmetros genéticos, com base nos componentes da variância, indicou influência do ambiente para todos os caracteres avaliados e dificuldades de seleção em solo ácido. A análise do dendograma gerado com base nas distâncias genéticas revelou a existência de dois grupos principais. Cruzamentos entre linhagens com desempenho superior e obtidas de famílias de diferentes grupos são potencialmente fonte para geração de populações de milho visando ao incremento da tolerância ao alumínio.
\end{abstract}

Palavras-chave: melhoramento genético, distância de Mahalanobis, Zea mays L.

\section{ABSTRACT \\ SELECTION FOR TOLERANCE TO ALUMINUM IN CORN BASED ON GENETIC PARAMETERS AND MULTIVARIATE ANALYSIS}

The improvement of plants, in the last 40 years, has pledged efforts in the search of maize genotypes with aluminum tolerance. The understanding of the existing variability and the genetic distance between genotypes serves as basis for crossings in breeding programs. The objective of this work was to study aluminum tolerance in maize based on multivariate analysis and genetic parameters in early generations. There were 74 families $\mathrm{F}_{3: 2}$ originated from two contrasting crosses for aluminum tolerance. The estimation of genetic parameters based on the components of variance, indicated the influence of the environment for all measured traits, which imposes difficulties for selection in acid soils. The analysis of the dendogram on the basis of the genetic distances disclosed the existence of two main groups. Crossings between inbreds with superior performance and families from different groups are potential source for maize populations to increase aluminum tolerance.

Key words: breeding, Mahalanobis distance, Zea mays L.

(1) Recebido para publicação em 20 de agosto de 2009 e aceito em 08 de abril de 2010.

(2) Fundação Centro de Experimentação e Pesquisa Fecotrigo (FUNDACEP), Setor Fitomelhoramento de milho. E-mail: larissa@fundacep.com.br; leo@fundacep.com.br

(3) Embrapa Cerrados, Caixa Postal 73301-970 Planaltina (DF). E-mail: leo.carson@cpac.embrapa.br

(4) Universidade Federal do Rio Grande do Sul (UFRGS), Faculdade de Agronomia, Departamento de Plantas de Lavoura, Av. Bento Gonçalves 1172, Caixa Postal 15100, 91501-970 Porto Alegre (RS). E-mail: jfbn@ufrgs.br $\left(^{*}\right)$ Autor correspondente. 


\section{INTRODUÇÃO}

A remoção de cátions básicos pela lixiviação, superior a sua reposição, e a degradação da matéria orgânica reduzem o pH do solo promovendo o aumento do alumínio $\left(\mathrm{Al}^{3+}\right)$ na solução do solo (BOHNEN, 1995). Em solos tropicais e subtropicais úmidos com altas precipitações pluviais, a acidez do solo e a toxicidade por alumínio são fatores determinantes para reduzida produtividade das culturas. $\mathrm{O}$ alumínio deprime $\mathrm{o}$ sistema de raízes em plantas, prejudicando a absorção de nutrientes, interferindo no desenvolvimento e, por consequência, diminuindo a produção de grãos (FoY, 1978). Por estas razões, o melhoramento de plantas tem empenhado esforços na busca de genótipos de milho com tolerância ao alumínio. Para tanto, o entendimento da natureza da herança do caráter é de extrema importância para a decisão dos procedimentos mais adequados a serem adotados para a seleção de genótipos com maior grau de tolerância. Existem divergências em relação ao modo de herança do caráter tolerância ao $\mathrm{Al}^{3+}$ em milho. Entretanto, em trabalhos recentes tem sido verificado que a capacidade geral de combinação é o parâmetro de maior magnitude em estudos de cruzamentos dialélicos (Morello et al., 2001; PAterniani e Furlani, 2002).

Diversos autores têm buscado a melhor forma de avaliar, estudar e selecionar plantas tolerantes ao alumínio em milho. Entre os métodos estudados estão hematoxilina (CAnÇAdo et al., 1999; Giaveno e Miranda Filho, 2000) e técnicas baseadas em solução nutritiva com derivações específicas em relação aos índices utilizados (MARTINS et al., 1999; MazzocATo et al., 2002). No entanto, plantas que possuem de baixa a média tolerância ao alumínio, nestes métodos, podem produzir híbridos superiores em condições de solo com baixa disponibilidade de fósforo e presença de alumínio (CANÇADOet al., 2002). Experimentos de campo são trabalhosos e variáveis devido à falta de homogeneidade do solo e circunstâncias climáticas. Porém, a comparação de genótipos selecionados em condições de campo é necessária (Giaveno e MirandA FILHO, 2002), pois a avaliação em campo da reação ao alumínio tóxico possibilita a adaptação ao ambiente e a seleção múltipla para caracteres agronômicos de interesse (BERTAN et al., 2006).

Análises de divergência genética têm sido utilizadas como critério no direcionamento de cruzamentos para espécies cultivadas como feijão (ELIAS et al., 2007) e aveia (BENIN et al., 2003). Em relação ao caráter tolerância ao alumínio, BERTAN et al. (2006) utilizaram esta estratégia para identificar genótipos promissores na formação de populações segregantes superiores em trigo. Neste contexto, o objetivo deste trabalho foi estudar o caráter tolerância ao alumínio em milho, com base em parâmetros genéticos e estatística multivariada, em famílias $\mathrm{F}_{3}$ submetidas ao solo ácido.

\section{MATERIAL E MÉTODOS}

Foram utilizadas cinco linhagens de milho comum (L20, L10, L09, L08, L06) Três linhagens foram previamente classificadas como sensíveis ao alumínio, L20 (em $\left.\mathrm{S}_{8}\right)$, L08 (em $\left.\mathrm{S}_{10}\right)$ e L06 (em $\left.\mathrm{S}_{9}\right)$, e as duas linhagens restantes, L10 (em $\left.S_{9}\right)$, L09 (em $S_{12}$ ) como tolerantes (MAzzocato et al., 2002). Estas linhagens foram cruzadas em um esquema dialélico para a obtenção de 10 híbridos $F_{1}$. Sementes $F_{2}$ foram obtidas por autofecundações e posteriormente avançadas até famílias $\mathrm{F}_{3}$. Os híbridos comerciais DKB747 (tolerante-T5), DKB350 (toleranteT4), DKB205 (sensível-T2), AS3466 (não informado-T3) e AS1533 (sensível-T1) foram utilizados como controles no experimento. Informações sobre os híbridos foram fornecidas pelas empresas cedentes.

O experimento foi instalado no município de Cruz Alta (RS), disposto em um delineamento de blocos casualizados com duas repetições. As parcelas experimentais corresponderam às famílias $\mathrm{F}_{3: 2^{\prime}}$ sendo compostas de duas linhas de 5,0 m espaçadas por 0,75 $\mathrm{m}$ com $0,20 \mathrm{~m}$ de espaçamento entre plantas. Foram realizados os seguintes tratos culturais: adubação de base com $250 \mathrm{~kg}$ ha $^{-1}$ de N-P-K (fórmula 12-30-20), adubação de cobertura com $150 \mathrm{~kg} \mathrm{ha}^{-1}$ de uréia, duas aplicações de herbicida (Sanson - 0,5 L ha-1 e Atrazina - 3,0 L ha-1) e três de inseticidas (Match - $300 \mathrm{~m} \mathrm{~L} \mathrm{ha}^{-1}$, Karate - 200 m L ha-1 e Engeo - 300 m L ha-1). O solo da área experimental foi amostrado a uma profundidade de $20 \mathrm{~cm}$, observando possíveis áreas heterogêneas. Foram coletadas duas amostras. Dentre as relevantes determinações os valores obtidos foram: $\mathrm{pH} 4,3$, argila $58 \%$, matéria orgânica 3,4\%, saturação por bases $8,5 \%$, saturação de $\mathrm{Al}^{3+} 64,2 \%$, cálcio trocável 1,1 $\mathrm{cmol}_{\mathrm{c}} \mathrm{dm}^{-3}$ e alumínio trocável 3,6 $\mathrm{cmol}_{c} \mathrm{dm}^{-3}$. Cinquenta dias após o florescimento, foram realizadas avaliações dos caracteres rendimento de grãos (REND), número total de espigas na parcela (NEP), número de espigas por planta (NEPLA), massa de grãos por espiga (ME) e estatura de planta (EST). Para REND e ME foi considerada apenas a massa dos grãos corrigida a $13 \%$ de umidade.

Com base nos resultados de recrescimento da raiz principal obtidos na geração $F_{2}$ do cruzamento dialélico, verificou-se que nas linhagens L09 e L06 os valores de capacidade geral de combinação foram relativamente superiores, e que o cruzamento L10 X L08, foi a combinação específica superior entre todos os cruzamentos avaliados (CONCEIÇão et al., 2009). Desta forma, para a análise estatística, foram utilizados os dados de 31 e 42 famílias $F_{3: 2}$ destes dois cruzamentos contrastantes, L09 X L06 (a) e L10 X L08 (b), respectivamente, totalizando 74 famílias. Os caracteres descritos foram submetidos à análise de variância utilizando-se o teste F. Para comparar as 
médias dos híbridos-testemunha empregou-se o teste de Duncan a 5\% de probabilidade. Os parâmetros genéticos foram estimados com base no esquema de análise de variância e sua esperança do quadrado médio. A importância relativa dos caracteres avaliados para a estimativa da dissimilaridade genética foi obtida por meio da participação dos componentes da distância generalizada de Mahalanobis $\left(\mathrm{D}^{2}\right)$, relativos a cada caráter, no total da dissimilaridade observada (SINGH, 1981). O dendograma obtido pelas distâncias de $D^{2}$ foi elaborado utilizando SAHN (sequential, agglomerative, hierarchic, non-overlapping clustering methods) com o método de agrupamento UPGMA (unweighted pairgroup method using the arithmetic average). Para a estimativa do ajuste entre a matriz de dissimilaridade e o dendrograma gerado, foi calculado o coeficiente de correlação cofenética (r). A análise estatística foi realizada utilizando os programas computacionais GENES (CRUZ, 2001), SAS SYSTEM v.8.1 (SAS INSTITUTE, 2000) e NTSYS-PC (RHOLF, 2000).

\section{RESULTADOS E DISCUSSÃO}

A análise do solo no local do experimento revelou condições adequadas para avaliação da tolerância ao alumínio, uma vez que o $\mathrm{pH}$ e a saturação por bases observados foram baixos e a saturação e o teor de alumínio trocável foram elevados. As determinações obtidas são similares a outros trabalhos desenvolvidos em campo relacionados com tolerância ao alumínio em trigo (Mistro et al., 2001) e milho (Morello et al., 2001), com solos contendo 3,6 $\mathrm{cmol}_{c} \mathrm{dm}^{-3}\left(\mathrm{pH} \mathrm{4,3)} \mathrm{e} \mathrm{5,2} \mathrm{cmol}_{\mathrm{c}}\right.$ $\mathrm{dm}^{-3}(\mathrm{pH} 4,2)$ de alumínio trocável respectivamente. $\mathrm{A}^{\mathrm{c}}$ área utilizada é considerada uniforme em termos de acidez, pois tem sido utilizada frequentemente para seleção de genótipos tolerantes ao alumínio em trigo. Os valores obtidos das testemunhas, para a maioria dos caracteres avaliados, reforçam esta afirmativa. Os híbridos tolerantes foram superiores $(p<0,05)$ para as variáveis REND, NEP e ME em relação aos híbridos sensíveis ao alumínio (Tabela 1). O coeficiente de variação com base nas testemunhas demonstrou um nível de precisão experimental elevado para condições de campo, variando de $21,5 \%$ a 9, $1 \%$, para rendimento de grãos (REND) e estatura de planta (EST) respectivamente (Tabela 1). O valor de 21,5\% para rendimento de grãos, caráter altamente influenciado pelo ambiente, pode ser explicado pela estiagem ocorrida durante a safra 2005/2006, na região de Cruz Alta, afetando os 20 primeiros dias do ciclo.

$\mathrm{Na}$ análise de variância univariada houve diferenças significativas para as variáveis avaliadas, indicando a existência de diferenças entre as famílias estudadas para cada cruzamento. As famílias dos cruzamentos L09 X L06 e L10 X L08 revelaram diferenças para REND, NEP e NEPLA $(p<0,01)$, enquanto as variáveis ME e EST as diferenças foram significativas $(p<0,05)$, apenas para as famílias do cruzamento entre as linhagens L10 e L08 (Tabela 2). Em estudo realizado com progênies de irmãos completos de uma população melhorada de milho tropical (SA-3), DUQUE-VARGAS et al. (1994) avaliaram os efeitos do alumínio tóxico em solos com diferentes graus de saturação de alumínio. Entre os caracteres avaliados - o rendimento de grãos, número de espigas por planta e estatura de planta - todos foram afetados quando comparados os resultados em ambiente ácido com o solo em condições normais. Embora houvesse uma elevada correlação genético-aditiva entre rendimento de grãos e número de espigas por planta, a seleção direta pelo rendimento de grãos seria mais efetiva em condições de solos ácidos. No presente estudo, em ambos os cruzamentos os valores máximos observados para $\operatorname{REND}\left(>3 \mathrm{t} \mathrm{ha}^{-1}\right)$ revelaram a existência de famílias com maior tolerância em

Tabela 1. Médias das variáveis observadas em campo, rendimento de grãos (REND), número de espigas por parcela (NEP), número de espigas por planta (NEPLA), massa de grãos por espiga (ME) e estatura de planta (EST) para os cinco híbridos testemunhas. Média geral e coeficiente de variação (C.V.)

\begin{tabular}{|c|c|c|c|c|c|}
\hline Híbridos & REND & NEP & NEPLA & ME & EST \\
\hline & $\mathrm{kg} \mathrm{ha}^{-1}$ & & & g & $\mathrm{cm}$ \\
\hline DKB 350 (T4) & $7254 \mathrm{a}$ & $19,5 \mathrm{a}$ & $0,9 \mathrm{a}$ & $135,5 \mathrm{a}$ & $131,7 \mathrm{a}$ \\
\hline DKB 747 (T5) & 5897 a b & $15,0 \mathrm{a} \mathrm{b}$ & $1,1 \mathrm{a}$ & $150,3 \mathrm{a}$ & $146,7 \mathrm{a}$ \\
\hline AS 3466 (T3) & $3832 \mathrm{bc}$ & $13,0 \mathrm{~b}$ & $0,9 \mathrm{a}$ & $110,5 \mathrm{ab}$ & $132,9 \mathrm{a}$ \\
\hline AS1533 (T1) & $3430 \mathrm{bc}$ & $13,5 \mathrm{~b}$ & $0,7 \mathrm{a}$ & $94,3 \mathrm{~b}$ & $126,7 \mathrm{a}$ \\
\hline DKB205 (T2) & $2978 \mathrm{c}$ & $12,0 \mathrm{~b}$ & $0,9 \mathrm{a}$ & $90,1 \mathrm{~b}$ & $117,5 \mathrm{a}$ \\
\hline Média Geral & 4678 & 14,6 & 0,9 & 116,3 & 131,1 \\
\hline C.V. $(\%)$ & 21,5 & 12,6 & 15,7 & 13,2 & 9,1 \\
\hline
\end{tabular}

Médias seguidas pela mesma letra não apresentam diferenças significativa segundo teste de Duncan a 5\% de probabilidade. T1 e T2: testemunhas sensíveis ao alumínio tóxico.

T4 e T5: testemunhas tolerantes ao alumínio tóxico, T3: não caracterizada. 
Tabela 2. Resumo da análise de variância univariada contendo causas da variação, graus de liberdade (GL), quadrados médios, valores máximos, valores mínimos e médias das variáveis avaliadas nas famílias $\mathrm{F}_{3: 2}$ dos cruzamentos entre linhagens contrastantes de milho L09 X L06 e L10 X L08

\begin{tabular}{|c|c|c|c|c|c|c|}
\hline Causas da variação & GL & REND & NEP & NEPLA & $\mathrm{ME}$ & EST \\
\hline & \multicolumn{6}{|c|}{ L09 X L06 } \\
\hline & & $\mathrm{kg} \mathrm{ha}^{-1}$ & & & $\mathrm{~g}$ & $\mathrm{~cm}$ \\
\hline Blocos & 1 & 517 & 6,4516 & 0,0131 & 1648,52 & 61,004 \\
\hline Famílias & 30 & $829608 * *$ & $24,9516 * *$ & $0,1363 * *$ & $669,19 \mathrm{~ns}$ & $250,101 \mathrm{~ns}$ \\
\hline Erro & 30 & 297694 & 7,4183 & 0,0437 & 557,34 & 193,097 \\
\hline Mínimos & & 129 & 1,0 & 0,1 & 8,8 & 63,3 \\
\hline Máximos & & 3571 & 16,0 & 1,3 & 173,9 & 143,3 \\
\hline \multirow[t]{2}{*}{ Média } & & 1336 & 7,3 & 0,5 & 72,2 & 107,1 \\
\hline & \multicolumn{6}{|c|}{ L10 X L08 } \\
\hline Blocos & 1 & 224298 & 2,2791 & 0,0377 & 176,78 & 890,910 \\
\hline Famílias & 42 & $735275 * *$ & $34,4070 * *$ & $0,0842 * *$ & $787,00 *$ & $293,178 *$ \\
\hline Erro & 42 & 255259 & 7,5886 & 0,0217 & 403,31 & 163,339 \\
\hline Mínimos & & 145 & 1,0 & 0,1 & 27,2 & 73,3 \\
\hline Máximos & & 3005 & 20,0 & 1,1 & 159,6 & 141,7 \\
\hline Média & & 1260 & 7,6 & 0,5 & 67,2 & 112,5 \\
\hline
\end{tabular}

Ns: não significativo. ${ }^{*},{ }^{* *}$ : significativo a $5 \%$ e $1 \%$ respectivamente pelo teste F. REND: rendimento de grãos. NEP: número de espigas na parcela. NEPLA: número de espiga por planta. ME: massa de grãos por espiga. EST: estatura de planta.

Tabela 3. Estimativa da variância genotípica, variância fenotípica, variância residual e coeficiente de determinação genotípico para as variáveis analisadas nos cruzamentos entre linhagens contrastantes de milho L09 X L06 e L10 X L08

\begin{tabular}{|c|c|c|c|c|c|}
\hline & REND & NEP & NEPLA & ME & EST \\
\hline & \multicolumn{5}{|c|}{ L09 X L06 } \\
\hline Variância genotípica & 265957 & 8,7667 & 0,0463 & 55,926 & 28,5021 \\
\hline Variância fenotípica & 414804 & 12,4758 & 0,0681 & 334,595 & 125,0506 \\
\hline Variância residual & 148847 & 3,7091 & 0,0218 & 278,668 & 96,5485 \\
\hline \multirow[t]{2}{*}{ Coeficiente determinação genotípico } & 64,12 & 70,27 & 67,91 & 16,71 & 2,79 \\
\hline & \multicolumn{5}{|c|}{ L10 X L08 } \\
\hline Variância genotípica & 240008 & 13,4092 & 0,0313 & 191,846 & 64,9197 \\
\hline Variância fenotípica & 367637 & 17,2035 & 0,0421 & 393,499 & 146,5892 \\
\hline Variância residual & 127629 & 3,7943 & 0,0109 & 201,653 & 81,6696 \\
\hline Coeficiente determinação genotípico & 65,28 & 77,94 & 74,22 & 48,75 & 44,29 \\
\hline
\end{tabular}

REND: rendimento de grãos, NEP: número de espigas na parcela, NEPLA: número de espiga por planta, ME: massa de grãos por espiga e EST: estatura de planta.

Tabela 4. Contribuição relativa das variáveis avaliadas para a dissimilaridade entre as 74 famílias $\mathrm{F}_{3: 2}$ de milho e testemunhas, obtida por meio da participação dos componentes da distância generalizada de Malahanobis

\begin{tabular}{lccc}
\hline \multirow{2}{*}{ Variáveis } & \multicolumn{3}{c}{ Dissimilaridade genética } \\
\cline { 2 - 4 } & Autovalores & $\%$ & $\%$ acumulada \\
\hline Rendimento de grãos & 38375,30 & 66,06 & 66,06 \\
Número de espigas por planta & 9830,46 & 16,92 & 82,98 \\
Número de espigas & 4663,10 & 8,03 & 91,00 \\
Estatura & 4650,93 & 8,01 & 99,01 \\
Massa de grãos por espiga & 575,71 & 0,99 & 100,00 \\
\hline
\end{tabular}

Fonte: SINGH, 1981. 
relação aos valores mínimos (Tabela 2). Entretanto, estes valores foram abaixo das testemunhas tolerantes (Tabela 1). Este fato justifica-se pelas testemunhas serem híbridos que possuem maior vigor e efeitos de heterose. Neste estudo, as testemunhas foram importantes apenas como referência para verificação da precisão do experimento e condições adequadas para diferenciação entre genótipos previamente classificados como tolerantes e sensíveis. Os valores míninos demonstram que genótipos sensíveis foram severamente afetados pelos efeitos tóxicos do alumínio (Tabela 2). Morello et al. (2001) avaliaram populações de milho adaptadas e exóticas, sob condições de solos ácidos, e verificaram que as populações que se sobressaíram atingiram rendimento acima de $3 \mathrm{t} \mathrm{ha}^{-1}$. O valor médio anotado pelos autores para a variável estatura de planta foi $187 \mathrm{~cm}$. Os valores máximos para as famílias $\mathrm{F}_{3: 2}$ dos cruzamentos L09 X L06 e L10 X L08 foram de 143,3 e 141,7 cm respectivamente (Tabela 2). Entretanto, efeitos de depressão endogâmica devem ter contribuído para as diferenças observadas. Giaveno e Miranda Filho (2002) com o intuito de introduzir genes favoráveis à tolerância ao alumínio da população SIKUANI ICA V-110 para a ESALQ PB2-3A, observaram os maiores valores de 4,04 $\mathrm{t} \mathrm{ha}^{-1}$ para rendimento de grãos e $152,7 \mathrm{~cm}$ para estatura de planta em subpopulações selecionadas.

Tanto nas médias quanto nas variâncias é importante identificar que proporção é devido a causas genéticas (Cruz e RegazzI, 1997). A estimativa dos parâmetros genéticos, com base nos componentes da variância, indicou influência do ambiente para todos os caracteres avaliados, destacandose a falta de variabilidade genética para ME e EST (Tabela 3). Os valores médios dos coeficientes de determinação genotípicos $\left(\mathrm{H}^{2}\right)$ para os caracteres REND, NEP e NEPLA refletem dificuldade de ganhos genéticos significativos por meio de seleção (Tabela 3). Entretanto, apesar da estimativa de $\mathrm{H}^{2}$ ser equivalente a herdabilidade no sentido amplo $\left(h^{2}\right)$, a falta de avaliações dos progenitores não possibilitou a estimativa de $h^{2}$. Da mesma forma, a estimativa de variância ambiental com base em repetições de famílias $\mathrm{F}_{3}$ pode ter sido superestimada. DUQUE-VARGAS

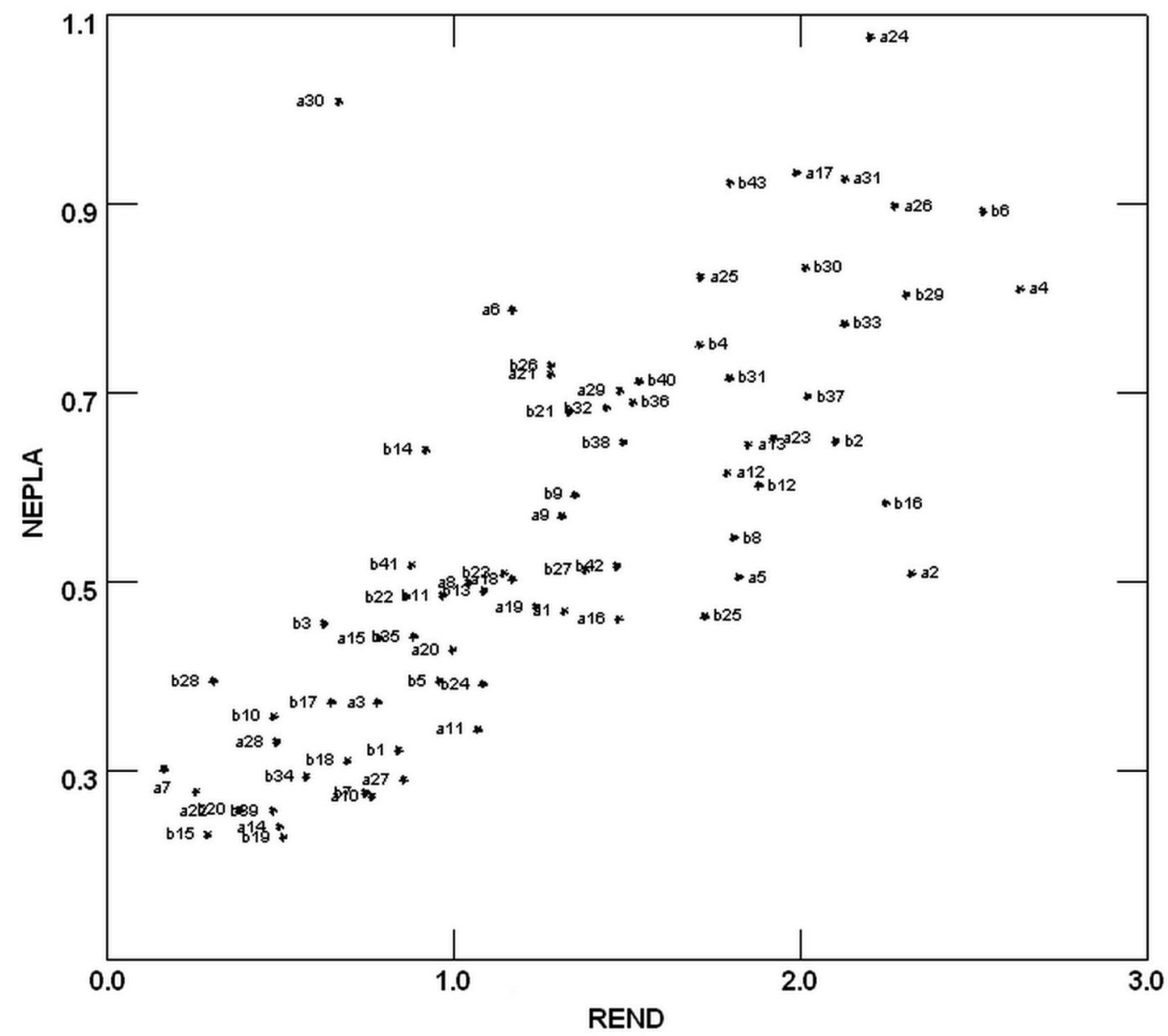

Figura 1. Gráfico de dispersão de pontos para as variáveis avaliadas número de espigas por planta (NEPLA) e rendimento de grãos (REND), em kg ha-1, para as 74 famílias $\mathrm{F}_{3: 2}$ de milho. 


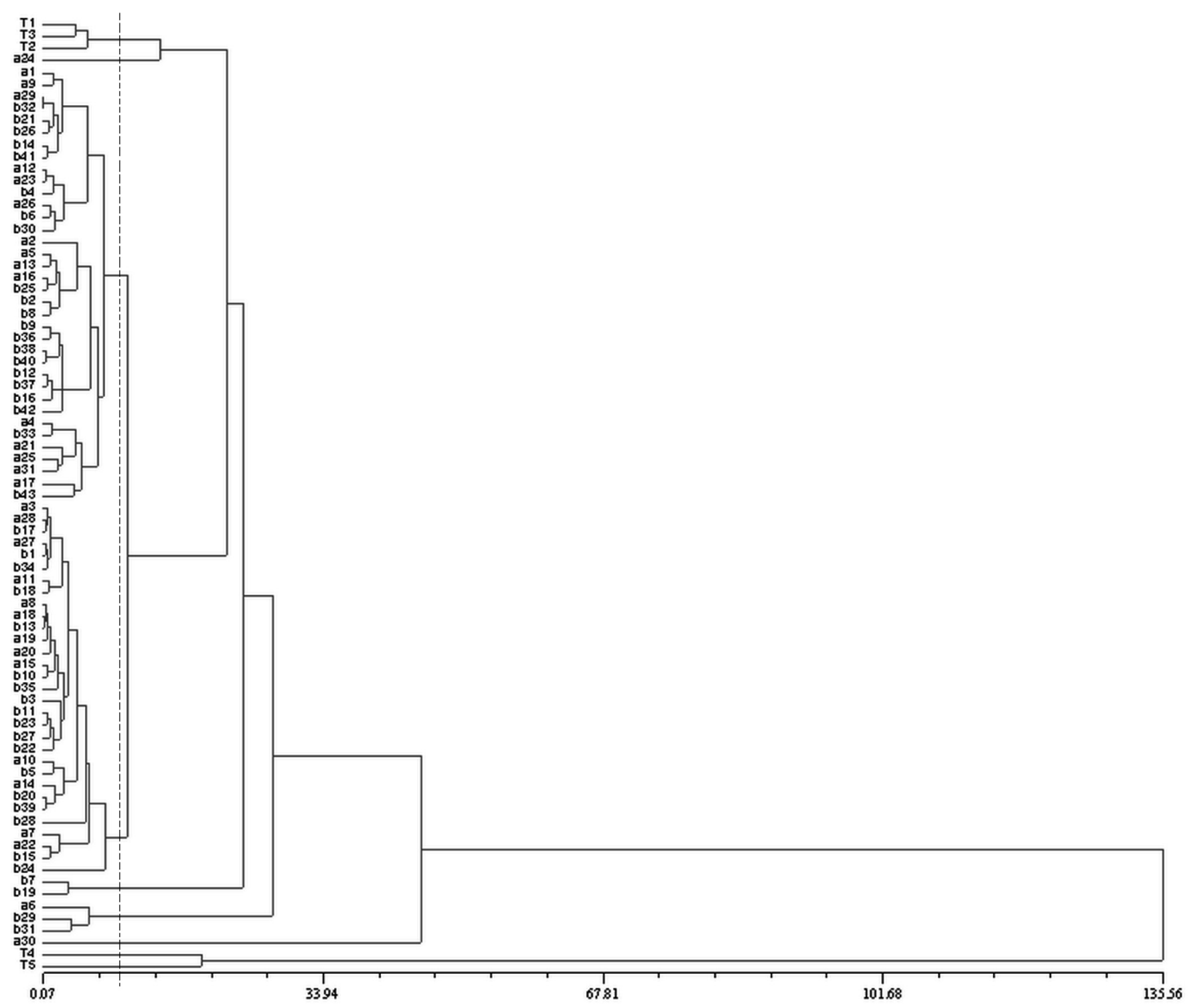

Figura 2. Dendograma representativo da dissimilaridade com base nas distâncias generalizadas de Mahalanobis.

et al. (1994) estimaram herdabilidades com base em médias de meio-irmãos, com valores de 36,3\%, 51,5 e $40,5 \%$ para rendimento de grãos, estatura de planta e número de espigas por planta. Em relação aos cruzamentos analisados (L09 X L06 e L10 X L08), não houve diferenças entre os valores máximos e mínimos observados para os caracteres avaliados, com exceção de ME (Tabela 2). Entretanto, os maiores valores de variância genotípica em relação à variância residual registrados para L10 X L08, quando comparados a L09 X L06, refletiram em valores superiores de $\mathrm{H}^{2}$. Desta forma, a seleção em famílias originadas do cruzamento L10 X L08 com base nos caracteres NEP, NEPLA, ME e EST poderá ser mais eficiente do que em famílias do cruzamento L09 X L06 (Tabela 3).
A partição dos componentes da distância generalizada de Mahalanobis revelou a maior importância dos caracteres REND $(66,06 \%)$ e NEPLA $(16,92 \%)$, em relação à dissimilaridade total, reunindo o conjunto de dados dos dois cruzamentos (Tabela 4). Desta forma, o REND, entre os caracteres avaliados, foi eficiente na diferenciação dos genótipos. A análise do dendograma gerado com base nas distâncias genéticas revelou a existência de nove grupos incluindo três grupos formados pelas testemunhas. Com base na observação do gráfico de dispersão das variáveis de maior contribuição para variação total (Figura 1), os genótipos com desempenho superior estão presentes em três grupos (Figura 2). O coeficiente de correlação cofenético de 0,93 sugere o ajuste entre a matriz de 
dissimilaridade e a representação gráfica obtida. Os grupos da metade superior do gráfico são compostos pelas famílias com desempenho superior para o caráter REND, incluindo as testemunhas. Apesar das testemunhas formarem grupos isolados, houve a separação entre híbridos tolerantes e sensíveis. A família a24 formou um grupo separado. Contudo, dois grupos abrangeram $90 \%$ das famílias. O critério utilizado para o ponto de corte foi a distância média ponderada $(9,8)$ pela representatividade dos híbridos e famílias $F_{3: 2}$ na distância total. O critério adotado permitiu a separação dos dois grupos e por consequência a formação de nove grupos. Não houve separação de grupos por cruzamento (Figura 2).

\section{CONCLUSÕES}

1. Existe variabilidade para o caráter tolerância com base nas variáveis estudadas para as famílias avaliadas.

2. Hibridações entre linhagens obtidas de famílias distantes, originadas de cruzamentos distintos e desempenho superior são promissoras para ganhos em tolerância ao alumínio.

3. Os caracteres REND e NEPLA são indicados como parâmetros a serem utilizados para selecionar linhagens superiores. Entretanto, a seleção deve ser aplicada em linhas avançadas devido aos valores de coeficiente de determinação genotípicos verificados nos dois cruzamentos estudados.

\section{AGRADECIMENTOS}

Ao $\mathrm{CNPq}$ pelos financiamentos e concessão de bolsa de doutorado do Programa de Pós-Graduação em Fitotecnia (UFRGS), ao primeiro autor, de 2002-2006. À FundaçãoCentro deExperimentaçãoePesquisa Fecotrigo (Fundacep) e Agroeste Sementes que contribuíram para realização deste trabalho. A Monsanto pelas amostras de sementes cedidas.

\section{REFERÊNCIAS}

BENIN, G.;CARVALHO,F.I.F;OLIVEIRA,A.C.;MARCHIORO, V.S.; LORENCETTI, C.; KUREK, A.J.; SILVA, J.A.G.; CRUZ, P.J.; HARTWIG, I. SCHMIDT, D.A.M. Comparações entre medidas de dissimilaridade e estatísticas multivariadas como critérios no direcionamento de hibridações em aveia. Ciência Rural, v.33, p.657-662, 2003.

BERTAN, I; CARVALHO, F.I.F; OLIVEIRA, A.C.; SILVA, J.A.G.; BENIN, G.; VIEIRA, E.A.; SILVA, G.O.; HARTWIG, I.; VALÉRIO, I.P.; FINATTO, T. Dissimilaridade genética entre genótipos de trigo avaliados em cultivo hidropônico sob estresse por alumínio. Bragantia, v.65, p.55-63, 2006.
BOHNEN, H. Acidez e Calagem. In: Princípios de fertilidade de solo. 1. ed. Porto Alegre: Departamento de Solos da Universidade Federal do Rio Grande do Sul, 1995. p.51-76.

CANÇADO, G.M.A.; LOGUERCIO, L.L.; MARTINS, P.R.; PARENTONI, S.N.; PAIVA, E.; BORÉM, A.; LOPES M.A. Hematoxylin staining as a phenotypic index for aluminum tolerance selection in tropical maize (Zea mays L.). Theoretical and Applied Genetics, v.99, p.747-754, 1999.

CANÇADO, G.M.A.; PARENTONI, S.N.; BORÉM, A.; LOPES, M.A. Avaliação de nove linhagens de milho em cruzamentos dialélicos quanto à tolerância ao alumínio. Pesquisa Agropecuária Brasileira, v.37, p.471-478, 2002.

CONCEIÇÃO, L.D.H.C.S.; TESSELE, C.; BARBOSA NETO, J.F. Diallel analysis and mapping of aluminum tolerance in corn inbred lines. Maydica, v.54, p.51-64, 2009.

CRUZ, C.D. Programa Genes: aplicativo computacional em genética e estatística. Viçosa: UFV, 2001. 648 p.

CRUZ, C.D.; REGAZZI, A.J. Modelos biométricos aplicados ao melhoramento genético. 2. ed. Viçosa: UFV, 1997. 390 p.

DUQUE-VARGAS, J.; PANDEY, S.; GRANADOS, G.; CEBALLOS, H.; KNAPP, E. Inheritance of tolerance to soil acidity in tropical maize. Crop Science, v.34, p.50-54, 1994.

ELIAS, H.T.; VIDIGAL, M.C.G; GONELA, A.; VOGT, G.A. Variabilidade genética em germoplasma tradicional de feijãopreto em Santa Catarina. Pesquisa Agropecuária Brasileira, v.42, p.1443-1449, 2007.

FOY, C.D.; CHANEY, R.L.; WHITE, M.C. The physiology of metal toxicity in plants. Annual Review of Plant Physiology, v.29, p.511-566, 1978.

GIAVENO, C.D.; MIRANDA FILHO, J.B. Rapid screening for aluminum tolerance in maize (Zea mays L.). Genetics and Molecular Biology, v.23, p.847-850, 2000.

GIAVENO, C.D.; MIRANDA FILHO, J.B.. Field comparison between selection methods at the maize seedling stage in relation to aluminum tolerance. Scientia Agricola, v.59, p.397-401, 2002.

MARTINS, P.R.; PARENTONI, S.N.; LOPES, M.A.; PAIVA, E. Eficiência de índices fenotípicos de comprimento de raiz seminal na avaliação de plantas individuais de milho quanto à tolerância ao alumínio. Pesquisa Agropecuária Brasileira, v.34, p.1897-1904, 1999.

MAZZOCATO, A.C.; ROCHA, P.S.G.; SERENO, M.J.C.M.; BOHNEM, H.; GRONGO, V.; BARBOSA NETO, J.F. Tolerância ao alumínio em plântulas de milho. Ciência Rural, v.32, p.1924, 2002.

MISTRO, J.C.; CAMARGO, C.E.O.; PETTINELLI-JÚNIOR, A. Avaliação de genótipos de trigo, de diferentes origens, em relação à toxicidade de alumínio. Bragantia, v.60, p.177-184, 2001. 
MORELLO, C.L.; MIRANDA FILHO, J.B.; GORGULHO, E.P. Partial diallel cross between exotic and adapted maize populations evaluated in acid soil. Scientia Agricola, v.58, p.313-319, 2001.

PATERNIANI, M.E.A.G.Z.; FURLANI, P.R. Tolerância à toxicidade de alumínio de linhagens e híbridos de milho em solução nutritiva. Bragantia, v.61, p.11-16, 2002.
ROHLF, F.J. NTSYSpc numerical taxonomy and multivariate analysis system v.2.1. Setauket: Exeter Software, 2000.

SAS Institute INC. The SAS system for windows v.8e. Cary: SAS Institute, 2000.

SINGH, D. The relative importance of characters affecting genetic divergence. The Indian Journal of Genetics \& Plant Breeding, v.41, p.237-245, 1981. 